\title{
Pesquisa-Formação: professoras da infância, suas narrativas e fotografias possibilitando paisagens ${ }^{1}$
}

Solange Maria de Oliveira Cruz ${ }^{2}$

A pesquisa-formação, que resulta na obra, é uma metodologia de pesquisa pautada na escuta pesquisador - participantes, por meio de diálogos e trocas que favorecem a reflexão.

O objetivo deste trabalho foi compreender, com o apoio de entrevistas narrativas de professoras da infância, as potencialidades do uso de fotografias do tempo de escola, no compartilhamento de lembranças num grupo de discussão, com a intenção de (re)significar o fazer docente e a construção de seu percurso formativo.

Tais narrativas permitiram compreender as histórias de vida de cada participante, contribuindo para a aprendizagem do grupo e foram cunhadas pela autora como "narrativas de subversão", por, segundo ela, poderem ali serem narradas, sem que houvesse a preocupação com os resultados da pesquisa, que, por fim, culminou numa autoformação por meio do compartilhamento de experiências inquietantes e provocativas.

As paisagens, a que se refere o título do livro, dizem respeito às lembranças evocadas pelas imagens nas fotografias e expressas nas narrativas das professoras sobre sua trajetória de vida escolar e seu percurso de formação docente.

Segundo a autora, o objetivo principal da pesquisa foi "pensar a formação de professores a partir da metodologia pesquisa-formação entrecruzada por narrativas e fotografias do tempo da escola de professoras que atuam na Educação Infantil, na cidade de Jundiaí-SP" (SANTOS; NACARATO, 2018, p.24).Com foco nos estudos biográficos, investigando, nos contextos vividos por estas profissionais, no momento em que eram alunas, os indícios da cultura escolar presentes em suas narrativas e fotografias, para, com isso, possibilitar uma (res)significação de suas práticas enquanto professoras.

O livro está organizado em cinco capítulos que, segundo Santos; Nacarato (2018, p.24), dialogam "com as professoras sobre as culturas escolares experienciadas por elas durante a

\footnotetext{
${ }^{1}$ Esse trabalho é fruto de tese.

2 Universidade São Francisco, Itatiba, solangecruzse@gmail.com.
} 
escolarização inicial", a fim de pensar sobre essas culturas, a experiência da escolarização inicial e as práticas na Educação Infantil dessas professoras da infância, quando posteriormente se tornaram docentes.

A obra propõe, então, um resgate da história da Educação Infantil mergulhando "por histórias de vida que atravessam a infância, a formação e a docência" (SANTOS; NACARATO, 2018, p.24), com especial interesse pelas histórias de vida dos sujeitos dessa experiência.

No PRELÚDIO: o arlequim que se colocou à escuta, que antecede o primeiro capítulo, a autora apresenta a foto "Surpresa na estrada", do fotógrafo Boris Kossoy. Recurso que se repete no início de cada capítulo, apresentando uma foto do referido fotógrafo, com o intuito de criar metáforas que estabeleçam relações com o texto, " na tentativa de desenvolver um fio condutor e produzir sentido ao texto" (SANTOS; NACARATO, 2018,p.33), além de, no meio dos capítulos, trazer fotos do tempo de escola dos participantes da pesquisa, objetivando narrar as histórias de cada um e de suas professoras de infância, num entrelaçamento com os processos formativos que experenciaram ao longo da vida e da carreira.

O capítulo um, intitulado CAMINHAR COM: fotografias e narrativas que ecoam das nossas infâncias, entrelaçam e nos constituem, traz a foto "O alfaiate" de Boris Kossoy. Nele, o grupo de professoras pesquisadas compartilham reflexões sobre sua infância, partindo das fotos apresentadas ao longo do capítulo, e das narrativas de suas lembranças, "a partir de uma escuta sensível e de construção dialógica" (SANTOS; NACARATO,2018, p.55), em que a própria autora participa, narrando sua infância e escolarização inicial, interagindo e conversando com os pares, a fim de reconstruir suas trajetórias de vida e de formação docente.

No capítulo dois, A ARTE DO ENCONTRO: navegando na e sobre nossas culturas escolares, com a foto "Sem título: Alemanha Ocidental, 1981", segundo a autora, ela tenta "romper com as culturas escolares" e "com a condição de aluno e de professor, de pesquisador e pesquisado" (SANTOS; NACARATO, 2018, p.79), referindo-se a ausência de controles no grupo, como de frequência e aplicação de provas e notas, que enfrentaram durante o percurso escolar desde a infância, ao mesmo tempo em que reafirma o compromisso que tinham uns com os outros, durante o processo de pesquisa, envolvendo-se no desejo de partilhar aprendizagens.

A autora utilizou biogramas ${ }^{3}$, onde registrou alguns marcos das histórias de vida e

\footnotetext{
${ }^{3}$ Ferramenta utilizada para estabelecer crono-topografias das trajetórias profissionais de professores e instituições de
} Periódico Horizontes - USF - Itatiba, SP - Brasil - e020035 
formação de cada participante, além de marcos referenciais de políticas públicas em educação e normas educativas (SANTOS; NACARATO, 2018, p.233-235),

Neste capítulo a autora relata "o encontro de si mesma" ocasionado pelas reflexões sobre as notas que fizera em campo como pesquisadora-narradora-formadora e o encontro das docentes com elas mesmas, por meio das narrativas ao longo do capítulo, entremeado de fotos, que as remeteu às lições aprendidas, treinadas, repetidas e memorizadas na escola, com crianças alinhadas e arrumadas nas fotos, demonstrando "uma certa imobilidade delas, atendendo as exigências de quem as fotografou" (SANTOS; NACARATO, 2018, p.107).

Suscita questões de corporeidade onde crianças aparecem imóveis em fotografias de escola, mesmo em contextos de festas, comemorações e apresentações às famílias, tornando-as crianças invisíveis no contexto das culturas escolares da época, aflorando um questionamento das culturas escolares atuais, e das atividades e avaliações propostas na escola por esses profissionais aos seus alunos nos dias de hoje.

No terceiro capítulo: A METÀFORA DA LOJA E A VITRINE: os (des)caminhos na formação de professores, a foto "Sem Título", ilustra a questão a ser discutida no capítulo: a constituição da identidade docente, que aqui é pesquisada através dos sujeitos-referência. Um capítulo com poucas fotografias, mas recheado de reflexões sobre, entre outras coisas, a questão da invisibilidade do professor na formação docente, em relação à "adoção de posturas verticalizadas pelas políticas públicas voltadas à formação de professores" (SANTOS; NACARATO, 2018, p.139).

Evidencia lacunas na formação inicial desses profissionais, e as especificidades da docência na educação Infantil, onde o ser professor de crianças pequenas na atualidade vem se redesenhando num novo olhar que "dê visibilidade às crianças e aos professores" (SANTOS; NACARATO, 2018, p.157), valorizando a diversidade de culturas escolares, além de desnaturalizar práticas hierárquicas segmentadas e fragmentadoras do conhecimento. O capítulo termina com um apelo para que deixem as crianças brincarem.

O quarto capítulo intitulado: NA ÁGORA: rodas, partilhas e resistências de um grupo de professores aprendentes, ilustrado pela fotografia "Carrossel", traz a ideia de movimento e

ensino. “Um biograma mostra uma síntese que traça uma história de vida e desenvolvimento profissional, contribuindo elementos espaço-temporais, dimensões-chave, marcos e pessoas relevantes em uma linha do tempo" (SEGOVIA; MARTOS; TITO, 2017, p.81, tradução nossa). Disponível em: file://C:/Users/Windows\%207/Downloads/5159-124611-SM.pdf. Acesso em 03 jul. 2019.

Periódico Horizontes - USF - Itatiba, SP - Brasil - e020035 
aproximação com o grupo de discussão-reflexão, cujo "carrossel está constituído por professoras da infância que carregam consigo a utopia e a vontade de re-significar as suas histórias de vida" (SANTOS; NACARATO, 2018, p.163), por meio das propostas trazidas para o coletivo e que impulsionaram o diálogo negociado.

O texto caminha por entre fotografias de escolas de vários lugares do mundo e reflexões sobre onde e como eram os espaços das aulas, cujas conclusões, de que não se podia estudar "la fora", e que "só podia brincar no final da aula", remete ao "no nosso tempo era assim". A autorapesquisadora participa trazendo suas próprias narrativas de "subversão" que, segundo ela, eram produzidas ao final de cada encontro do grupo.

No quinto capítulo RASCUNHOS DE NÓS: provisoriedades e re(invenções) para a docência, a fotografia "At the Library", encerra o percurso da pesquisa, nele as professoras da infância foram levadas a re(pensarem) suas trajetórias de vida e de formação profissional, por meio de narrativas atravessadas por imagens impressas em fotografias dos acervos pessoais que, além de revelarem cenas do percurso de vida pessoal e escolar de cada uma, também contribuíram para a constituição de sua identidade docente, pelo significado que trouxeram para a discussão - reflexão, quando em grupo exercitaram a artes do encontro, da escuta e das narrativas de vida.

Neste último capítulo, a autora traz para a discussão a aprendizagem que permeou a relação orientadora/orientanda, "pouco citada nos trabalhos acadêmicos" (SANTOS; NACARATO, 2018, p.202), refletindo o lugar ocupado pela orientadora no processo de mediação estabelecido, entre ambas, no percurso da pesquisa.

Combinando fotografias do tempo da escola e narrativas, a autora conclui o quanto esses dois instrumentos de pesquisa podem fomentar reflexões, construir, potencializar e lapidar aprendizagens, de forma colaborativa, à medida que este tipo de trabalho dá voz às criançasprofessoras em formação durante a pesquisa.

As reflexões levaram as docentes do grupo a pensar sobre as culturas escolares que vivenciaram enquanto crianças, e a partir delas, revelarem desejos de mudanças em seus fazeres docentes, bem como a "necessidade de olhar a criança nas suas potencialidades, e de priorizar o brincar na Educação Infantil" (SANTOS; NACARATO, 2018, p.204), superando o modelo transmissivo de educação bancária a que foram submetidas, evidenciadas em fotografias em que se pode observar crianças estáticas, impecavelmente arrumadas, esperando o momento do flash 
fotográfico captar sua "imagem de escolar" da época.

Por fim, relata algumas dificuldades em fazer a pesquisa- formação, marcadas, principalmente, pelas dúvidas sobre quais materiais fotográficos selecionar e a angústia em transformar o projeto de pesquisa em uma tese diante das incertezas enfrentadas no percurso.

UM POSFÁCIO... MAIS UMA NARRATIVA DE SUBVERSÃO... EM CENA A ORIENTADORA traz a foto "Irmãs", do acervo da professora orientadora (e coautora do livro), em que a mesma declara não ter fotos de infância na escola para compartilhar. Numa constatação-reflexão indaga e afirma: "Quais são as minhas memórias da educação Infantil? Não as tenho! Iniciei minha escolarização no 10 ano primário" (SANTOS; NACARATO, 2018, p.210), e a partir daí segue rememorando sua trajetória de vida pré-escolar, por meio de um "causo", que conta sua história com fotografias, sua frustação por não tê-las quando criança, e da emoção ao receber de presente, de uma prima, uma foto sua com as irmãs mais velhas (a mesma que ilustra o posfácio).

A narrativa da professora orientadora sobre seu tempo de educação infantil, embora não tenha feito parte da pesquisa, está carregada de emoção ao contar sobre a foto e sobre a constatação que essa única fotografia lhe proporciona a possibilidade de se imaginar criança. Assim, tem-se a construção de mais uma "experiência narrativa" (SANTOS; NACARATO, 2018, p.211), em cujas memórias e reflexões, podemos vislumbrar o início de uma trajetória de vida.

\section{Referências}

SANTOS, C. A.; NICARATO, A. M. Pesquisa-formação: professoras da infância, suas narrativas e fotografias possibilitando paisagens. Curitiba: CRV, 2018.

Recebido em setembro 2019.

Aprovado em maio 2020. 